\title{
The CAMBRIA case: Learning through experience
}

\section{Escalante, Juan Esteban ${ }^{a}$ and Aguilar-Barrientos, Sara ${ }^{b}$}

${ }^{a}$ Department of Organization and Management, Universidad EAFIT, Colombia, ${ }^{\mathrm{b}}$ Department of International Business, Universidad EAFIT, Colombia

\begin{abstract}
Experiential learning contributes to the development of thought-related abilities, such as critical thinking and creative thinking. This article evinces the contribution of this theoretical and conceptual proposal through a specific experience with the CAMBRIA project, a solar electric vehicle built at Universidad EAFIT, that potentiated aspects related to multidisciplinary work amongst undergraduate students and, in turn, brought about pedagogical changes at the Institution. CAMBRIA opened a panorama for exploring new alternatives in the teaching-learning process and, through participation in non-simulated activities, led to the restatement of certain core aspects of the University's educational activities. An analysis of this topic also leads to the formulation of a learning and competency acquisition model. Finally, project results and conclusions are presented, which include elements derived from the proposed model and testimonies from some of the participating students, who were interviewed in depth.
\end{abstract}

Keywords: Experiential learning; Critical thinking; Creative thinking. 


\section{Introduction}

Educational institutions focus their efforts on successfully adapting their academic programs to a world in constant transformation (Celuch \& Slama, 1999), which implies conceptual and technological requirements that transcend current market demands (Class, 2011). This dynamic of change requires adopting pedagogical strategies that promote the appropriation of relevant skills for cultivating creativity, critical thinking and permanent learning in persons (Peters, 2015). CAMBRIA, a pioneering project from CREA, the experimentation, leadership and development center at Universidad EAFIT (Colombia) is part of an institutional plan that seeks new schemes and mechanisms for generating, transmitting and adopting knowledge. This initiative was conceived under experiential learning guidelines, and materialized through a solar electric vehicle, designed and manufactured over less than six months and with an approximate budget of 150,000 USD, with the goal of participating in the iLumen European Solar Challenge. This is a 24-hour long competition held on September 24 and 25 at the Zolder circuit in Belgium and in which 12 solar vehicles, along with 2 Teslas, underwent a unique endurance test. This article seeks to analyze the role of experiential learning in the acquisition of abilities and competencies associated with critical thinking and creative thinking, using CAMBRIA and its affiliated groups as a specific frame of reference.

\section{Theoretical Framework}

\subsection{Critical Thinking}

The topic of critical thinking has become of considerable theoretical and pedagogical interest (Bailin, Case, Coombs, \& Daniels, 1999). This topic's spectrum transcends the educational field, with special attention being paid to it by companies, entities that understand the impact of understanding and managing the complexities associated with working environments (Hilton, 2008). Although the concept of critical thinking admits multiple positions (O'Neill \& Dluhy, 1997), there is a certain degree of consensus regarding its constituent features, including purpose, motivation, and goal orientation. The literature highlights the importance of this topic for problem solving, inference formulation, probability calculation, and decision-making (Halpern, 1999). Critical thinking also demands identifying and defying assumptions, contextual analysis, and the ability to explore different courses of action (Brookfield, 1987). It deals with the capacity to evaluate situations in a disciplined manner, foreseeing the implications for any stakeholder groups involved therein (Yousefi \& Mohammadi, 2016). 


\subsection{Creative Thinking}

Creative thinking plays a fundamental role in overcoming obstacles in all environments (Marguc, Van Kleef, \& Förster, 2015). Creativity helps to solve problems that cannot be solved from other points of view or under conditions that have not been analyzed previously (Stuhlfaut \& Vanden Bergh, 2014). It deals with a process for generating ideas, a process of reinvention and redefinition that has the underlying goal of reaching novel and original solutions. Its relevance can be found in countless scientific, artistic, theoretical and practical contexts (Stokes, 2011). Despite the dissimilar findings when trying to explain the nature and origin of creative thought, and existing theoretical differences, it can be affirmed that creative thinking occurs, at least in individuals, in situations that require novel solutions (Mumford, Blair, Dailey, Leritz, \& Osburn, 2006). Under this framework, and having in mind certain abilities and attributes which cannot be achieved under the traditional teaching models, experiential learning scenarios have demonstrated to be a successful trigger of the skills and characteristics associated with creative thinking. (Ayob, Hussain, Mustafa, \& Shaarani, 2011)

\subsection{Experiential Learning}

The theoretical and conceptual proposal of experiential learning is founded on the contributions of developmental psychology, which asserts that knowledge is generated through the transformation of experience (Kolb, Boyatzis, \& Mainemelis, 2002). According to Kolb (1984) experiential learning is composed of a spiral cycle involving concrete experience, reflection on experience, the creation of abstract concepts, and, out of this reflection, their application to new concepts. This approach is useful if one considers the supporting evidence for the role of experiential learning in the development of critical thought (Bigelow, 1991) and the dissimilar transformational effect of existing learning experiences (Bird, 2015).

Experiential learning contemplates a process through which knowledge is created through the transformation of experience, resulting from the combination of acquired experience and its evolution, emphasizing the potential of discovery in an individual's learning process (Kolb, 1984). Its impact on the development of multiple abilities inherent to workplace dynamics is highlighted (Bell, Kanar, \& Kozlowski, 2008), as well as on the high levels of commitment achieved in students, who require more and more pedagogies that will capture their interest and desire to learn (Lovelace, Egger, \& Dick, 2016). However, it must be pointed out that the thought-related competencies developed under experiential learning are highly contextual. This means that, unlike other abilities, such as athletic abilities, those related to thinking cannot be separated from an understanding of the nature and the purpose of the task to be performed (Bailin et al., 1999). 


\section{The Model}

The following is a model that uses experiential learning to leverage the adoption of competencies linked to critical thinking and creative thinking. This proposal seeks to understand the way in which the tools for deploying experiential learning can contribute concretely to the development of faculties inherent to critical thinking and creative thinking.

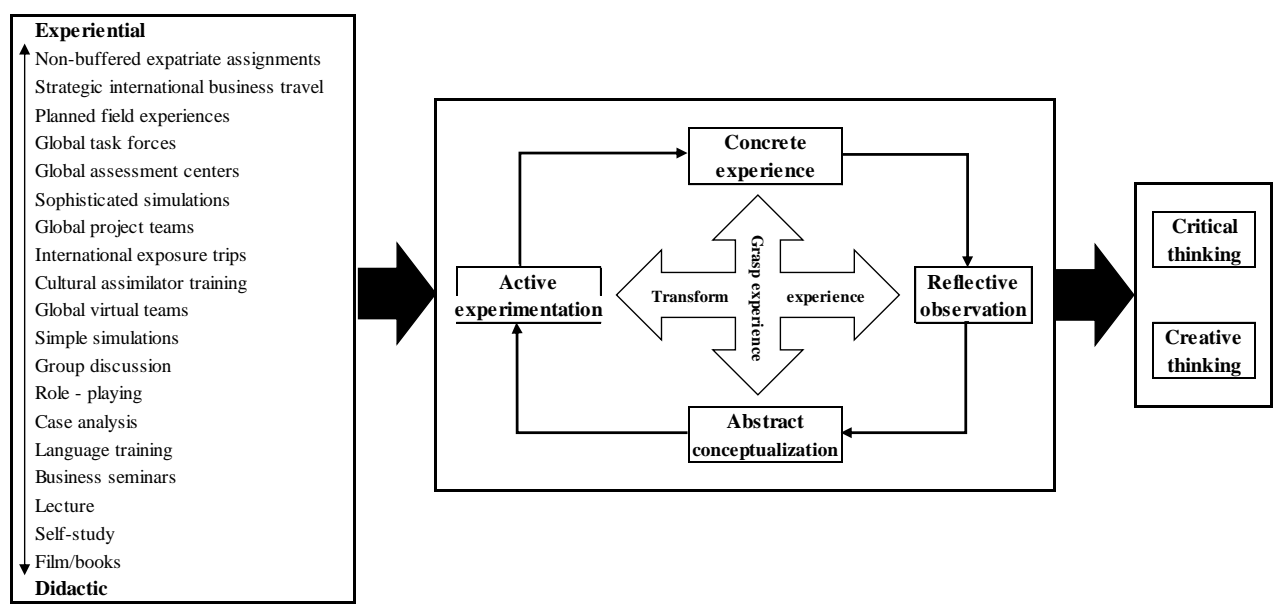

Figure 1. Experiential-critical thinking learning model. Prepared by the authors, taking from Bird (2015) and Kolb (1984)

The model contemplates an analysis of learning experiences through a continuous scale that allows locating activities according to their transformational power and the volume and quality of the feedback received from the source of knowledge (Oddou \& Mendenhall, 2012). The use of the didactic-experiential continuum restricts the possibility of determining the potential impact of the experience, as it focuses exclusively on the pedagogical approach used, and leaves out reflexive observation, a critical component of the learning experience. To overcome this limitation, the links between the pedagogical scales of learning practices, experiential learning, critical thinking and creative thinking need to be analyzed. To do this, the proposals made by Kolb (1984) are turned to. The involvement of reflexive observation, abstract conceptualization, active experimentation and concrete experience emphasizes an ability to interpret and reinterpret events, always considering context and feedback, and therefore requires more from individuals than presence and mechanical repetition (Bennet \& Salonen, 2007). This concludes the theoretical proposal, which provides an account of a binding sequential model between pedagogical practice, experiential learning, critical thinking and creative thinking. 


\section{The Experience}

In May 2016, CAMBRIA was set up as a pioneering project for CREA, Universidad EAFIT's experimentation, leadership and development center. The idea arose out of an exhaustive analysis of the initiative's viability by several members of the Business School (dean, department heads, professors, students). It was structured with the purpose to develop complementary learning mechanisms which would promote the acquisition of competencies through integral initiatives under the guidelines contemplated in experiential learning. The team was put together after a series of invitations sent out to all students in the University's undergraduate programs, with a view to setting up a multidisciplinary group. 25 students from diverse schools (nine from Business, nine from Engineering, six from Humanities, and one from Sciences) participated. The technical leadership of this challenge was assumed by an MIT alumnus who is an expert in the manufacture of solar vehicles, and supported administrative and organizationally by the deans and five professors from the Institution's Business and Engineering Schools, who followed up functions linked to process design, budget planning and execution, investments and expenditures; activity and scheduling control and follow-up, and managed sponsors, press and dissemination. During execution, a weekly agenda of deliverables and committees was configured that served a double purpose: one, to validate compliance with scheduled activities, and two, to solve any accidents or unforeseen events that might arise along the way. Activities were performed over a period of 90 days, a record time for this type of project. A distant, seemingly impossible dream was achieved thanks to the commitment and passion of the CAMBRIA students, who defied all barriers and difficulties to finally participate in the iLumen European Solar Challenge.

\section{Results}

CAMBRIA's performance in terms of design, speed and innovation, surpassed all the team's expectations, including those of outside persons that witnessed the iLumen European Solar Challenge. But perhaps the most important achievements were made on the pedagogical and learning levels, both by the participants and by the institution. For the Business School, the preparation and execution of CAMBRIA represented an inflection point in its pedagogical activities, encouraging reflection around experiential learning and challenge-based learning activities, considering their curricular effect, in terms of competencies and skills, especially within a framework of critical and creative thinking, and it is suggested that these need to be strengthened to deal with non-simulated organizational challenges with high-impact implications.

In-depth interviews were carried out with five students participating in the CAMBRIA project, and with their testimonies they bore witness to the challenge's positive effect on 
their lives, both academic and personal. CAMBRIA allowed them to experience what they had learned in the classroom in the real world, as it was a non-simulated space in which events that occurred had tangible consequences. Besides, the contrast between theory and practice together with the experience acquired, allowed students to analytically evaluate different alternative solutions to problems, contributing to their creative thinking (Mumford et al., 2006) and to improving their decision-making criteria by strengthening their critical thinking skills (Brookfield, 1987; Halpern, 1999; Yousefi \& Mohammadi, 2016). The fact of learning by doing meant students had to find new approaches for managing difficult situations (Marguc et al., 2015), work in teams, perform in high-pressure situations, and value and manage resources and time. The students catalog CAMBRIA as an experience that changed their lives and made a mark on them. Some of those interviewed stated they had found themselves and had found a family in the other participants. All of them highlighted that the project's demands in terms of commitment and responsibility, heightened their own motivation and resilience (Marguc et al., 2015) and their capacity for adapting to new environments (Stokes, 2011). Table 1 presents some of the results achieved, classified into two dimensions: personal and academic. This learning process helped close the cycle proposed by Kolb, as it contemplated the stages of reflexive observation, abstract conceptualization, active experimentation, and concrete experience (Kolb, 1984).

Table 1. Dimensions of learning achieved

\begin{tabular}{ccc}
\hline Academic & \multicolumn{2}{c}{ Personal } \\
\hline $\begin{array}{c}\text { Experiencing classroom learning } \\
\text { in reality }\end{array}$ & Identity & $\begin{array}{c}\text { Management of difficult } \\
\text { situations }\end{array}$ \\
$\begin{array}{c}\text { Comparing theory and practice } \\
\text { Autonomous learning of new } \\
\text { concepts } \\
\text { Multidisciplinarity }\end{array}$ & Social relations & Teamwork \\
& Resivation & Work under pressure \\
& & Resource management \\
\hline
\end{tabular}




\section{Conclusions}

CAMBRIA can be considered a revolutionary, transformative initiative compared to traditional learning methods, a project framed by experiential learning that became an institutional landmark and opened the spectrum for the use of new complementary methodological proposals. The scheme for recruiting and involving participants in the project also represented a challenge in and of itself, as the students showed a strong interest in the experience, independently of the area of knowledge they were involved in and their academic performance. The impact of CAMBRIA evinces an evolution in learning-teaching methods towards non-stimulated environments that imply autonomous learning, informed decision-making, resource management, and real-life problem solving.

\section{References}

Ayob, A., Hussain, A., Mustafa, M. M., \& Shaarani, M. S. (2011). Nurturing creativity and innovative thinking through experiential learning. Procedia - Social and Behavioral Sciences, 18, 247-254. doi:10.1016/j.sbspro.2011.05.035

Bailin, S., Case, R., Coombs, J. R., \& Daniels, L. B. (1999). Common misconceptions of critical thinking. Journal of Curriculum Studies, 31(3), 269-283.

Bell, B., Kanar, A., \& Kozlowski, S. W. (2008). Current issues and future directions in simulation-based training in North America. International Journal of Human Resource Management, 19(8): 1416-1434.

Bennett, J., \& Salonen, B. (2007). Intercultural communication and the new american campus. Change, 39(2), 46-50.

Bigelow, J. (1991). Managerial skills: Explorations in practical knowledge. Thousand Oaks, CA: Sage Publications

Bird, A. (2015). Introduction: Experiencing the World In V. Taras, \& M. A. GonzalezPerez (Eds.). The Palgrave Handbook of Experiential Learning in International Business (pp. 3-11). London, England: Palgrave Macmillan.

Brookfield, S. D. (1987). What it means to think critically. In S. D. Brookfield (Ed.), Developing critical thinkers: Challenging adults to explore alternative ways of thinking and acting (pp. 3-14). San Francisco, CA: Jossey-Bass.

Celuch, K., \& Slama, M. (1999). Teaching critical thinking skills for the 21st century: An advertising principles case study. Journal of Education for Business, 74(3), 134-139.

Class, C. B. (2011). Teaching new technologies and life-long learning skills: A sample approach and its evaluation. International Journal of Advanced Corporate Learning, 4(4), 10-19.

Halpern, D. F. (1999). Teaching for critical thinking: Helping college students develop the skills and dispositions of a critical thinker. New Directions for Teaching and Learning, 80, 69-74. 
Hilton, M. (2008). Skills for work in the 21st century: What does the research tell us? Academy of Management Perspectives, 22(4), 63-78.

Kolb, D. A. (1984). Experiential learning: Experience as the source of learning and development. Englewood Cliffs, NJ: Prentice Hall.

Kolb, D. A., Boyatzis, R. E., \& Mainemelis, C. (2002) Experiential on cognitive, learning and thinking styles. In R. J. Sternberg, \& L. F. Zhang (Eds.). Perspectives learning theory: Previous research and new directions (pp. 227-248). Mahwah, NJ: Lawrence Erlbaum.

Lovelace, K. J., Eggers, F., \& Dyck, L. R. (2016). I do and I understand: Assessing the utility of web-based management simulations to develop critical thinking skills. Academy of Management Learning and Education, 15, 100-121. doi:10.5465/amle.2013.0203

Marguc, J., Van Kleef, G. A., \& Förster, J. (2015). Welcome interferences: Dealing with obstacles promotes creative thought in goal pursuit. Creativity and Innovation Management, 24(2), 207-216. doi:10.1111/caim.12071

Mumford, M. D., Blair, C., Dailey, L., Leritz, L. E., \& Osburn, H. K. (2006). Errors in creative thought? Cognitive biases in a complex processing activity. Journal of Creative Behavior, 40(2), 75-109.

Oddou, G., \& Mendenhall, M. E. (2012). Global leadership development. In M. E. Mendenhall, J. Osland, A. Bird, G. Oddou, M. Maznevski, M. J. Stevens, \& G. K. Stahl. Global leadership: Research, practice and development (2nd ed.) (pp. 215 - 239). London, Routledge

O'Neill, E. S., \& Dluhy, N. M. (1997). A longitudinal framework for fostering critical thinking and diagnostic reasoning. Journal of Advanced Nursing, 26(4), 825-832.

Peters, R. A. (2015). Anchored learning and the development of creative, critical thinking and life-long learning skills. Teaching Public Administration, 33(3), 221-240. doi:10.1177/0144739415581077

Stokes, D. (2011). Minimally creative thought. Metaphilosophy, 42(5), 658-681. doi:10.1111/j.1467-9973.2011.01716.x

Stuhlfaut, M. W., \& Vanden Bergh, B. G. (2014). Creativity is ...: A metaphoric model of the creative thought process. Journal of Marketing Communications, 20(6), 383-396. doi:10.1080/13527266.2012.710644

Yousefi, S., \& Mohammadi, M. (2016). Critical thinking and reading comprehension among postgraduate students: The case of gender and language proficiency level. Journal of Language Teaching and Research, 7(4), 802-807. doi:10.17507/jltr.0704.23 